\title{
Currículo, desenho animado e diversidade
}

\author{
Maria Heloisa de Melo Cardoso* \\ Verônica dos Reis Mariano Souza** \\ José Adelmo Menezes de Oliveira***
}

\section{Resumo}

Este estudo tem como principal objetivo caracterizar o gênero textual Desenho Animado como ferramenta pedagógica a ser utilizada na Educação Básica para tratar do tema diversidade, adotando-se a noçáo de currículo como um fenômeno em permanente processo de (re)elaboração, marcado por múltiplas e diferentes concepções teórico-epistemológicas, mas sempre como tempo/lugar para a formação de sujeitos críticos, criativos e intelectualmente independentes. A partir do tema central, elegeuse o desenho "Como treinar o seu dragáo" com o intuito de analisar seus personagens na relação com a diversidade e o comportamento inclusivo. Teve-se, ainda, a intenção de ressaltar a escola como instância legítima para desenvolver um trabalho curricular com um sentido e significados educativos que expressem diferentes visões de mundo e de valores que estimulem a convivência harmoniosa entre as pessoas. Com este artigo, além de se sugerir o desenvolvimento de uma metodologia para trabalhar a diversidade, pretende-se contribuir para reflexôes e discussóes sobre o processo de ensino e aprendizagem, que são recorrentes, atuais e necessárias para o fazer pedagógico.

Palavras-chave: Diversidade; Desenho animado; Recurso pedagógico.

* Professora mestre em Educação pela Universidade Federal de Sergipe, São Cristóvão, Sergipe, Brasil.

** Professora doutora em Educaçáo pela Universidade Federal da Bahia, Salvador, Bahia, Brasil.

*** Professor doutor em Educação na Universidade Federal de Sergipe, São Cristóvão, Sergipe, Brasil. 


\section{Curriculum, animated drawing and diversity}

\section{Abstract}

The main objective of this study is to characterize the textual genre Cartoon as a pedagogical tool to be used in Basic Education to deal with diversity, adopting the notion of curriculum as a phenomenon in permanent process of (re) elaboration, marked by multiple and different theoretical-epistemological conceptions, but always as time I place for the formation of critical, creative and intellectually independent subjects. From the central theme, the design How to Train Your Dragon was chosen in order to analyze their characters in relation to diversity and inclusive behavior. It was also intended to highlight the school as a legitimate body to develop a curricular work with an educational meaning and meaning that express different worldviews and values that encourage harmonious coexistence between people. With this article, in addition to suggesting the development of a methodology to work on diversity, it is intended to contribute to reflections and discussions about the teaching and learning process, which are recurrent, current and necessary for the pedagogical doing.

Keywords: Diversity; Cartoon; Pedagogical resource.

\section{Introdução}

Para que se esclareça a posição dos autores deste artigo sobre a temática proposta, toma-se de empréstimo a obra Discurso sobre a origem e os fundamentos da desigualdade entre os homens, na qual Rousseau (2015) estabelece uma diferenciação entre desigualdades naturais ou físicas (produzidas pela natureza) e desigualdades sociais (produzidas pelas relações de domínio econômico, religioso e político). $\mathrm{Na}$ opinião do filósofo, para alcançar os ideais igualitários, seria necessário eliminar as segundas desigualdades e não as primeiras, pois estas são fatores de enriquecimento para a sociedade. Para ele, a desigualdade causada por circunstâncias sociais deve ser combatida, e é exatamente assim que o personagem Soluço, do desenho animado "Como treinar seu dragão",produzido por Peter Hastings nos estúdios da Paramount Pictures, nos Estados Unidos, no ano de 2010, age ao longo da trama. De compleição física bem diferente dos demais habitantes da ilha nórdica, o pequeno Soluço é um viking desprovido de um corpo forte e musculoso, condição que lhe impóe um tratamento discriminatório por parte dos membros de sua tribo. A diferença entre Soluço e seus conterrâneos vai além do aspecto físico. Ele se diferencia do seu grupo sobretudo pela clareza que possui de que sua condição física menos robusta não o torna um sujeito de segunda classe. O gênero textual Desenho Animado se caracteriza, como tantos outros, como ferramenta comunicacional flexível, dinâmica, e potencialmente adequada para o debate de temas da vida cidadã em sala de aula. Segundo Marcuschi (2010), os gêneros textuais são fenômenos históricos, de forte apelo comunicacional, e vinculados à vida social. O enredo do desenho animado oportuniza, de modo cuidadoso, o tratamento da temática Diversidade nas classes de todas etapas da Educação Básica, exatamente como pressupóem as Diretrizes Curriculares Nacionais da Educação Básica - DCNEB1. 
Art. 9o A escola de qualidade social adota como centralidade o estudante e a aprendizagem, o que pressupóe atendimento aos seguintes requisitos:

I - revisão das referências conceituais quanto aos diferentes espaços e tempos educativos, abrangendo espaços sociais na escola e fora dela;

II - consideração sobre a inclusão, a valorização das diferenças e o atendimento à pluralidade e à diversidade cultural, resgatando e respeitando as várias manifestaçóes de cada comunidade;

De acordo com esse documento, o currículo da Educação Básica deve perceber a criança, os adolescentes, os jovens e adultos como sujeitos sócio-histórico-culturais, providos de direitos, dentre eles o acesso à escola pública, gratuita e de qualidade. No projeto de nação previsto na Constituição brasileira, reafirmado no Estatuto das Crianças e dos Adolescentes e pelas DCNEB, a educação escolar é o lastro para a formação para a cidadania, e condição para o acesso aos bens econômicos, culturais, estéticos e políticos no atual contexto social.

Os problemas relativos às desigualdades, abordados por Rousseau (2008) em meados do século XVIII, se seguiram até atingir o nosso tempo, com grande atualidade. As questôes que levantou em seu século, não são, ainda hoje, de modo algum obsoletas, uma vez que se expressam no paradigma da diferença, conceito criado a partir do pressuposto de que "somos biológica e culturalmente diferentes. Assim, o desafio atual não é mais de considerar que somos todos iguais, mas sim que somos todos diferentes" (FREITAS, 2008, p. 12).

Aplicado a pessoas, o vocábulo "diferença" revela uma multiplicidade de perspectivas de que se reveste nas práticas sociais e na medida em que se apoia em alguns marcadores, tais como diferenças físicas, intelectuais e culturais, segundo diversas conotaçóes. Acerca do assunto, Carvalho (2008, p. 17) assim se manifesta:

\begin{abstract}
Em outras palavras, a diferença não é percebida como um fato isolado e sim como resultante de relaçóes sociais fundamentadas em valores que, uma vez desrespeitados, produzem as diferenças [...] Como as relaçóes sociais ocorrem em todos os lugares de uma formação social, na prática, a experiência vivida e as decorrentes das relaçôes sociais não ocorrem em espaços mutuamente exclusivos.
\end{abstract}

Essa formulação estimula a ideia "de uma simultaneidade de livres organizaçôes espaciais que acentua a escolha, a diversidade e a diferença” (HARVEY;SOBRAL, 2000, p. 242). Aqui, em particular, a diversidade abrange a discussão em torno das minorias excluídas socialmente, por apresentarem condiçóes físicas, intelectuais, sociais, linguísticas, dentre outras que diferem dos padróes legitimados pela sociedade e que distinguem o indivíduo, a exemplo de ser branco ou negro, ser homem ou mulher, ter deficiência ou não, ser rico ou pobre.

Sob o eixo da diversidade, busca-se a igualdade que é ressignificada em função das relaçôes estabelecidas entre os sujeitos e o contexto social. No entanto, para assegurar a efetiva igualdade, não basta uma concepção. É preciso criar contextos em que as pessoas sejam aceitas face ao que podem e querem fazer, e não confinadas àquilo 
que outras pessoas pensam que elas podem e querem fazer (FREITAS, 2008). E, na perspectiva claramente funcional que introduz o conceito de diversidade, a atenção passa a centrar-se na escola que trata de ajustar a sua oferta de educação à peculiaridade de grupos cada vez mais heterogêneos.

Assim, discutir educação e diversidade, dentro da ambiência acadêmica, faz sobressair a necessidade de se dar um novo enfoque ao modelo tradicional de intervenção pedagógica na sala de aula. $\mathrm{O}$ arranjo curricular de toda Educaçáo Básica deve partir do estudante como um sujeito histórico que, enquanto brinca, interage e participa da vida em coletividade, constrói sua identidade. Para as DCNEB, a proposta pedagógica das creches, pré-escolas e escolas deve proporcionar às crianças, aos adolescentes, aos jovens e aos adultos, oportunidades de aprendizagens por meios de diversas linguagens, inclusive da arte, incluindo-se as artes visuais, a exemplo do desenho animado, conforme se verifica no Artigo 13,

$\$ 2^{\circ} \mathrm{Na}$ organização da proposta curricular, deve-se assegurar o entendimento de currículo como experiências escolares que se desdobram em torno do conhecimento, permeadas pelas relaçóes sociais, articulando vivências e saberes dos estudantes com os conhecimentos historicamente acumulados e contribuindo para construir as identidades dos educandos.(Grifo nosso).

Para tanto, o professor deve viabilizar aprendizagens ativas, em situaçôes educativas que permitam uma leitura crítica da realidade. Isso leva a pensar que os desenhos animados podem assumir, na escola, não somente a função de diversão e entretenimento, mas associado à atividade pedagógica. O tema central deste artigo é, portanto, o uso do desenho animado como estratégia no processo de ensino e aprendizagem sobre a diversidade.

Nessa direção, com a pretensão de contribuir para o combate às desigualdades, considera-se que a abrangência desse tema conduz à tarefa de delineá-lo a partir de um modelo extraído de uma cultura partilhada por todos. Dentro dessa concepção, o presente estudo busca oferecer "uma ajuda autêntica, aquela em cuja prática, os que nela se envolvem se ajudam mutuamente crescendo juntos, no esforço comum de conhecer a realidade que busca transformar" (FREIRE, 2014, p. 15).

Objetivando caracterizar o desenho animado como ferramenta pedagógica para abordar o tema diversidade, elegeu-se o desenho "Como treinar o seu dragão" com o intuito de analisar seus personagens na relação com a diversidade e o comportamento inclusivo. A intenção é ressaltar a escola como instância legítima para desenvolver um trabalho curricular com um sentido e significados educativos que expressem diferentes visóes de mundo e de valores que estimulem a convivência harmoniosa entre as pessoas. A esse respeito, há o entendimento que, ao longo da escolarização, as visôes de mundo dos educandos vão sendo confrontadas pela cultura sistematizada que faz parte do currículo escolar.

Trazendo a questão para o âmbito da diversidade, no enfoque de Louro (2000), os sujeitos que, por alguma razão ou circunstância escapam da norma, são tomados como minoria e colocados à margem das preocupaçôes de um currículo ou de uma 
educação que se pretenda para a maioria. No entanto, para a referida autora, a diversidade deve estar na ordem das coisas e no cerne das concepçóes curriculares de uma escola que se mostre como instituição que atende aos desafios de reunir alunos diferentes, tornando-se espaço de formação humana. É no ambiente escolar que a diversidade pode ser respeitada ou negada, motivo pelo qual deve ser reconhecida e contextualizada no currículo.

Com esse entendimento, pensar as questôes ligadas à diversidade através de imagens e narrativas, seja visual ou audiovisual, como objeto de discussão e análise, é propor uma abordagem aprofundada que leve em conta aspectos diferenciados. A estrutura simbólica da comunicação visual, no caso específico deste artigo o desenho animado, constitui sistema arbitrário de sentidos e significados.

Há de se considerar, portanto, que expandir o entendimento sobre determinado fenômeno é "produzir uma abrangência mais elucidativa das instituiçóes humanas” (GIDDENS, 2012, p. 43). Recorrendo ao filósofo Karl Popper (1972), Giddens (2012, p. 40) prossegue seu ponto de vista ao reconhecer que "toda ciência repousa sobre areia movediça. Em ciência, nada é certo, e nada pode ser provado, ainda que o empenho científico nos forneça a maior parte da informação digna de confiança sobre o mundo a que podemos aspirar".

Com base no pensamento de Kuhn (2006), evidencia-se que nenhuma teoria nova está de acordo com todos os fatos conhecidos do campo que se pretende explicar. Portanto, quando a comunidade aceita um paradigma (modelo, padrão), o que ela está aceitando, na realidade, é uma promessa de resolução dos problemas futuros, promessa que se impóe sobre as outras com base no sucesso obtido nas resoluçóes dos problemas já examinados. Assim, importa identificar, no setor educacional, segundo Nonata (2007, p. 263), "os fenômenos que condicionam novas leituras da realidade, geram para ela novas explicaçóes, portanto novas leis e, consequentemente, novas racionalidades e novas práticas". E, pensar novas práticas instiga à discussão sobre o desenho animado como recurso metodológico tendo como eixo a diversidade e seus reflexos na educação.

\section{Diversidade versus escola}

Ao longo da história depara-se com diversas formas de viver, de pensar e de encarar as diferenças em cada sociedade, contextualizadas por sua cultura, costumes, ideologias, ou seja, paradigmas, os quais, como a própria história, não são estáticos. $\mathrm{Na}$ linha de pensamento de Berger e Luckmann (2011), a cultura é definida como construção social da realidade, o que implica a criação, reproduçáa e difusão de sistemas de atitudes e modos de agir, de costumes e instituiçóes, valores espirituais e materiais. Discorrendo sobre o assunto, Hall (2005, p. 51) argumenta que a cultura é um discurso, um modo de construir sentidos que influencia diretamente a concepção que se tem sobre si mesmo, estando tais sentidos "contidos nas estórias que são contadas, memórias que conectam seu presente com seu passado e imagens que dela são construídas". O ensino e a aprendizagem devem ser relacionados aos seus usos sociais, e a diversidade faz parte da condição humana. Aprender a respeitar as diferenças consiste numa das liçóes da escola. 
Na relação cultura e diversidade, esta assume o contorno de um conjunto de diferenças reais ou atribuídas que, incorporadas pela sociedade, representam a cultura dominante como sendo a norma. Essa norma expõe o conflito entre distintos modelos de sociedade, um produtor da exclusão e outro baseado na equidade. De acordo com tais modelos, aqueles que nâo se enquadram nos ideários preestabelecidos de força, beleza, riqueza, juventude, produtividade e normalidade (FERREIRA, 2007), fariam parte de uma minoria social e, por isto mesmo, sujeita à exclusão.

Isso leva ao seguinte relato de Silva (2009, p. 136): "a história da humanidade nos mostra que as sociedades têm grandes dificuldades em lidar com as diferenças, seja de ordem física, psíquica ou sensorial”. Esse fato reflete exemplos de eliminação daqueles que são diferentes e desiguais, daqueles padróes tidos socialmente como normais. O pensamento de Silva (2009) vai ao encontro das concepçôes formuladas por Ferreira (2007) no tocante ao conceito, ainda predominante na atualidade, que as pessoas deveriam se enquadrar em padróes e normas que desconsideram a diversidade como um direito humano e fator de pluralidade e enriquecimento.

Não obstante, diante de um movimento que busca superar a exclusão, a travessia para uma sociedade mais humanizada está associada à consolidação de uma escola inclusiva, entendida como o lócus adequado para "constituir consciências críticas, efetivamente autônomas e criativas, capazes de construir sociedades mais justas - voltadas para a solidariedade e o respeito pelo outro" (FERREIRA, 2007, p. 553). Desse modo, na sociedade atual, a escola tem assumido, progressivamente, funçóes cada vez mais complexas, das quais algumas eram consideradas atribuiçôes de outras instâncias educativas, como a família, por exemplo. Tal ampliação de suas funçóes pode ser considerada como imposição da realidade, marcada pela velocidade com que ocorrem mudanças em todas as áreas do saber e do fazer humanos.

Na Resolução CNE/CEB n. 4/2010, a temática Diversidade ocupa um lugar de centralidade no processo educacional das crianças, dos adolescentes, dos jovens e dos adultos, conforme se vê no

Art. $3^{\circ}$ As Diretrizes Curriculares Nacionais específicas para as
etapas e modalidades da Educação Básica devem evidenciar o seu
papel de indicador de opçóes políticas, sociais, culturais, educa-
cionais, e a função da educação, na sua relação com um proje-
to de Nação, tendo como referência os objetivos constitucionais,
fundamentando-se na cidadania e na dignidade da pessoa, o que
pressupóe igualdade, liberdade, pluralidade, diversidade, respeito,
justiça social, solidariedade e sustentabilidade. (Grifo nosso).

De acordo com Carvalho (2008), a sociedade tem apontado para a necessidade de ressignificar o papel da escola para além do pedagógico, reconhecendo que a ela vêm se somando atribuiçôes políticas e sociais, principalmente em função da diversidade de seu alunado e da complexidade das demandas oriundas do contexto socioeconômico, político e cultural. Nesse ambiente, o esforço é direcionado à efetivação de uma educação de qualidade para todos, de um espaço único para a convivência e a aprendizagem (MARQUES; MARQUES, 2006). Esses autores auxiliam na compreensão de que uma educação de qualidade abrange, necessariamente, a ideia de uma escola que seja capaz de atender à variedade de características de seus alunos. 
Esse novo modelo desvela e destaca as diferenças culturais, sociais, étnicas, religiosas, de gênero, enfim, a diversidade humana, redefinindo uma educação voltada para a cidadania plena, que reconhece e valoriza as diferenças (MANTOAN, 2003). A escola vem sendo pensada, com considerável relevância e centralidade entre os teóricos e os formuladores de políticas educacionais, como um lugar privilegiado para a formação de uma sociedade mais justa, humana e democrática na aceitação das diferenças, por isto mesmo, uma sociedade culturalmente inclusiva.

Por conseguinte, a problematização sobre as questôes que lidam com a diversidade tem se ampliado progressivamente no âmbito da sociedade brasileira, aumentando o número de estudos e divulgaçóes de trabalhos que exploram esta temática nos mais diversos campos, a exemplo de uma pesquisa realizada, em 2009, pela Fundaçãoo Instituto de Pesquisas Econômicas (FIPE) a pedido do Ministério da Educação (MEC).O estudo, com base em entrevista com mais de 18,5 mil alunos, pais e mães, diretores, professores e funcionários de 501 instituiçóes de ensino público em todo o país, concluiu que as escolas são ambientes onde o preconceito é bastante disseminado entre todos os atores, fato que trouxe preocupação ao MEC, que demonstrou a necessidade de se melhorar o espaço escolar mediante o desenvolvimento de açóes de respeito à diversidade.

Para Vianna e Ridenti (1998, p. 96), "se a questão da diferença é fundamental para (entender) as relaçóes que ocorrem na escola, por ser um espaço de sociabilidade e de práticas culturais, muitas vezes essas práticas acabam traduzidas em estereótipos e preconceitos", haja vista que a instituição escolar pode contribuir tanto para a celebração como para a negação da diversidade. Nessa discussão, considerar a diversidade é condição sinequa non para o desenvolvimento efetivo dos cidadãos e das cidadãs, sendo possível afirmar, em uma primeira análise, a importância da escola que, enquanto palco de diferenças, permite ao aluno relacionar-se diariamente com os outros, distante do controle familiar.

Isso porque o ambiente escolar é espaço de diferentes relaçôes sociais, refletindo a diversidade cultural presente na sociedade e no qual se evidencia que "diferentes costumes, crenças, etnia e todos que compóem a cultura, frequentam, diariamente, as salas de aula" (CANDAU, 2012, p. 24). Desse modo, a autora acredita que a educação escolar precisa ajudar professor e alunos a compreenderem que a diferença entre pessoas é saudável e enriquecedora, sendo preciso valorizá-las e respeitá-las tais como elas são, com suas características próprias e individualizadoras. Acerca do assunto, Munanga (2003, p. 189) confirma que:

A escola, como parte integrante dessa sociedade que se sabe preconceituosa e discriminadora, mas que reconhece que é hora de mudar, está comprometida com essa necessidade de mudança e precisa ser um espaço de aprendizagem onde as transformaçóes devem começar a ocorrer de modo planejado e realizado coletivamente por todos os envolvidos, de modo consciente. [...].

É fato, portanto, que a educação deve abranger processos educativos que possibilitem às pessoas superar preconceitos, estimulando-as a viverem práticas sociais livres de discriminaçáo, tornando-se significativa para o desenvolvimento dos futuros 
cidadãos. Os processos de educação são importantes não só para a elaboração de diretrizes, procedimentos e práticas pedagógicas que desmitifiquem concepçốes preconceituosas, como também pela capacidade que têm de erradicar as diversas maneiras de discriminação. Fica evidente, nessa perspectiva, a necessidade do professor se situar na dinâmica dos novos processos de ensino e aprendizagem, em novas técnicas capazes de promover uma aprendizagem crítica e reflexiva.

\section{desenho animado: um olhar sobre a diversidade}

Conforme os esclarecimentos de Sancho (2001), a expressão audiovisual, de modo geral, costuma ser aplicada às técnicas e aos métodos informativos, documentários ou didáticos, nos quais são utilizados elementos visuais, imagens fixas ou em movimento, e elementos auditivos, palavra, música e/ou efeitos sonoros. No campo do ensino, inclui-se como audiovisual desde os meios mais simples e de apoio postos a serviço do discurso verbal do professor, até as obras que o utilizam como forma de expressão autônoma. Envolve tanto as tecnologias que não dependem de recursos elétricos ou eletrônicos, quanto aquelas que necessitam de um ou vários desses recursos para se desenvolverem.

Sob o ponto de vista de Leite (2003), o audiovisual é um sistema diferenciado de expressão, uma maneira específica de processar as informaçôes, uma linguagem.

$\mathrm{Na}$ comunicaçáo audiovisual, o processamento das informaçóes representa o resultado das interaçôes entre as imagens, as músicas, o texto verbal, os efeitos sonoros, dentre outros, constituindo-se uma linguagem de síntese que produz, no receptor, uma experiência unificada desses elementos expressivos.

Complementando essa visão, Férres (2001) ressalta que, nesse jogo de interaçôes, as emoções cumprem um papel decisivo, pois são portadoras de ideias, dos significados. No ambiente educacional, a veiculaçáo de imagens e sons torna-se efetiva por meio de um programa audiovisual bem concebido e projetado, apresentado didaticamente de modo mais eficaz que outros recursos como os livros- texto, cadernos de leitura, fichas de atividades, histórias em quadrinhos, contos, dentre outros usados no sistema escolar. A esse respeito, o Artigo $13, \S 3^{\circ}$, Item VII da resolução que instituiu as Diretrizes Curriculares Gerais da Educaçáo Básica assevera que a organização curricular deve promover o"estímulo à criação de métodos didático-pedagógicos utilizando-se recursos tecnológicos de informaçáo e comunicaçáo, a serem inseridos no cotidiano escolar, a fim de superar a distância entre estudantes que aprendem a receber informação com rapidez utilizando a linguagem digital".

Levando-se em conta que os meios audiovisuais são recursos que os professores podem utilizar em sala de aula, integrá-los à prática docente ajuda a criar uma realidade comunicativa capaz de otimizar o processo de ensino e aprendizagem. $\mathrm{Na}$ perspectiva do desenho animado, pode-se pensá-lo como um recurso pedagógico, como uma possibilidade de educação, pois "sua capacidade narrativa se transmuta em uma didática inebriante para formar percepçôes do mundo" (DANTAS JÚNIOR, 2012, p 67). Acredita-se, portanto, que ele possa contribuir na formaçáo dos estudantes no que diz respeito à diversidade e, consequentemente, de construção da igualdade, posto que: 
[...] uma educação por meio da arte pode proporcionar o desenvolvimento do ato de julgar pelo estímulo aos novos olhares acerca da vida e da realidade. A arte pode e deve ampliar a diversidade cultural, posto que a redução da percepção do outro limita meus horizontes de contato e alimenta práticas e ideias intolerantes, assim como a redução da capacidade de pensar está diretamente vinculada à redução da capacidade de sentir (DANTAS JUNIOR, 2012, p. 77).

Assim, no "reconhecimento radicalmente perturbador de que é apenas por meio da relação com o Outro, da relaçấo com aquilo que não é, com precisamente aquilo que falta [...], que o significado positivo de qualquer termo pode ser construído" (HALL, 2005, p. 110), faz-se uma exploração crítica do desenho animado selecionado para o estudo, pela riqueza e possibilidades que permite sobre o tema. Sua escolha se deu, principalmente, pelo eixo social apresentado na forma da diversidade biológica, que se ressalta no jovem personagem, e na questão da alteridade, manifesta na relação de interação e dependência com o dragão, sob a conotação do diferente. $\mathrm{O}$ desenho contém inúmeras mensagens que explicitam a necessidade de tolerância às diferenças do outro.

Como já mencionado anteriormente, o desenho animado "Como treinar seu dragáo" traz como protagonista um rapaz chamado Soluço, filho do chefe de uma tribo de vikings que habitavam uma ilha nórdica, continuamente atacada por dragóes em procura de alimentos. Apesar de esperto e aventureiro, ele era visto como um jovem atrapalhado e franzino para os padróes de um guerreiro, cujo perfil, adotado por aquela sociedade, integrava força e brutalidade como características mais importantes. Stoico, pai de Soluço, preocupado com a honra da família, temia que o jovem, por falta de atributos físicos suficientes, não pudesse substituí-lo, um dia, como líder da aldeia.

Em busca de ser reconhecido pelo pai e, em simultâneo, pela aldeia, como um verdadeiro viking, para ele, o primeiro passo consistia em matar um dragão. Por um golpe do destino, Soluço acerta um dos mais temidos pela tribo, um dragáo da espécie Fúria da Noite, mas somente o encontrando no dia seguinte, ferido e escondido em meio à vegetação da floresta. Com parte da calda mutilada devido ao golpe desferido por Soluço, o temido dragáo perde, temporariamente, a capacidade de voar. Mais uma vez, a película nos coloca diante de dois seres marcados por diferenças: Soluço, por não ser, não pensar e não agir conforme os demais membros de sua tribo; e o dragão Fúria da Noite, agora com uma deficiência adquirida, incapacitado para voar.

Ao aproximar dois seres vítimas do preconceito, esse desenho animado pode se constituir numa ferramenta pedagógica potente para os professores e professoras trabalharem muitas temáticas relativas à vida cidadã, inclusive a Diversidade. No filme, é exatamente por conta da diferença que marca a vida do pequeno viking Soluço e do dragáo Fúria da Noite, que o inesperado acontece e os dois se tornam amigos. Esse aspecto do filme pode se constituir suporte pedagógico para ajudar os estudantes a reafirmarem o respeito à diferença, à tolerância e à solidariedade.Com o convívio, 
desenvolvem uma relação de amizade e cumplicidade, descobrindo - jovem e dragão - que tudo o que haviam aprendido um sobre o outro estava errado. O conhecimento sobre o outro possibilita a eliminação de preconceitos e a posterior transformaçáo daquela aldeia, que adotou novos rumos, tornando-se um espaço de convivência e harmonia entre humanos e dragóes.

Desse contexto, é possível ao docente integrar, de modo geral, o processo de socializaçáo à solução de conflitos constituídos pelo preconceito, este definido por Amaral (2002, p. 17) como "um conceito que formamos aprioristicamente, anterior, portanto, à nossa experiência [...]”. A autora acrescenta que a personificação do preconceito se dá através de estereótipos, com base em algumas características, como negros, judeus, homossexuais, deficientes, dentre outros. Uma vez detectados por sua suposta anormalidade, tais sujeitos são isolados ou carregam as marcas dos preconceitos e dos estigmas, criados historicamente e facilmente identificados na sociedade. O termo estigma, marca ou impressão, desde os gregos, era empregado, tal como descrito por Goffman (2012), como indicativo de uma degenerescência: os estigmas do mal, da loucura, da doença. Prossegue o autor:

Na Antiguidade Clássica, através do estigma, procurava-se tornar
visível qualquer coisa de extraordinário, mau, sobre o status de
quem o apresentasse. O estigma 'avisavà a existência de um es-
cravo, de um criminoso, de uma pessoa cujo contato deveria ser
evitado. Na Era Cristá, dois níveis foram acrescentados à metáfora
do estigma: num, de natureza sagrada, o estigma era sinal corporal
de graça divina; no outro, era uma alusão médica de distúrbio
físico (GOFFMAN, 2012, p. 11).

Conforme se pode apreender, as regras são criadas pelos grupos sociais, de tal modo que o tratamento dispensado à diferença está intimamente ligado à trama das relaçóes sociais. Portanto, perante a exposição até aqui traçada, espera-se que a escola se prepare para lidar com a diversidade, problemática que deve perpassar o currículo escolar. É nesse sentido que o desenho animado pode servir à educação como um recurso que propicia discutir, desmistificar e repensar padrôes de comportamentos estabelecidos.

\section{Considerações finais}

$\mathrm{Na}$ atualidade, mudanças obrigam a escola a fazer alteraçóes em seu ambiente, pois é fato que a educaçáo contemporânea náo comporta mais o ensino conservador e repetitivo baseado na reproduçáo dos conhecimentos. Diante disso, avalia-se que o audiovisual pode desempenhar uma funçáo eficaz para despertar o interesse dos alunos pelo assunto dado em sala de aula, de maneira a criar questionamentos e abrir perspectivas. Convém ressaltar que junto aos meios audiovisuais usados em sala de aula, o desenho animado se caracteriza como apoio e fonte de informaçóes, permitindo a criação de um novo ambiente de aprendizagem, onde o processo curricular é vivenciado de forma mais rica e instigante para a implementação de novos códigos de expressão. 
Especificando-se o tema da diversidade na perspectiva do desenho animado como recurso pedagógico, a escolha da produção a ser utilizada como referência, neste artigo, deu-se em funçáo dos valores e das mensagens que transmite, e que constituem ideologias e princípios capazes de atuar na formação do indivíduo. As diversidades existentes em seu contexto permitem ensinar aos alunos e alunas sobre a importância da valorização das diferenças. A comprovação do alcance do desenho animado como recurso pedagógico pode ser encontrada na vitalidade com que a linguagem audiovisual se consolidou na sociedade contemporânea,

Essas consideraçôes respondem aos objetivos deste trabalho, lembrando que, para tratar das relaçóes entre diversidade e educaçáo, é necessário fomentar a reflexão sobre práticas educacionais na escola. E, no exercício de reflexão apresentado no presente estudo, considera-se o desenho animado como uma possibilidade de ensino e aprendizagem para a formação das geraçóes presentes e futuras, afirmando-se como um instrumento de validade científica para ser usado na educação escolar.

\section{Referências}

AMARAL, L.A. Diferenças, estigma e preconceito: o desafio da inclusão. In: OLIVEIRA, M. K.de; REGO, T. C.; SOUZA, D. Tr. R. (orgs.). Psicologia, educaçáo e as temáticas da vida contemporânea. São Paulo: Moderna, 2002, p. 233- 248.

BERGER, P.; LUCKMANN, T. A construção social da realidade. 5. ed. Petrópolis: Vozes, 2011.

BRASIL. Ministério da Educação. Análises descritivas sobre preconceito e discriminação nas escolas públicas. Brasília: FIPE, 2009, p. 335.

BRASIL. Resolução n. 4, de 13 de julho de 2010. Estabelece as Diretrizes Curriculares Nacionais Gerais da Educação Básica. Diário Oficial da União, Brasília, DF, 09 jul. 2010.

CANDAU, V. M. Somos todos/as iguais? Escola, discriminação e educação em direitos humanos. 2. ed. Rio de Janeiro: DP\&A, 2012, 136 p.

CARVALHO, R. ÉEscola inclusiva: a reorganização do trabalho pedagógico. Porto Alegre: Mediação, 2008, $152 \mathrm{p}$.

COMO TREINAR MEU DRAGÃO. Produção de Peter Hastings. Estados Unidos: Paramount Pictures, 2010. CD (98 min.).

DANTAS JÚNIOR, H. S. Esporte e cinema: possibilidades pedagógicas para a educação física escolar. Cadernos de Formaçáo RBCE, p. 67-78, set. 2012.

FERREIRA, M. E. C. O enigma da inclusão: das intençốes às práticas pedagógicas. Educação e Pesquisa, v. 3, n. 2, p. 67-78, set./dez. 2007.

FÉRRES, J. Televisão e educaçáo. Porto Alegre: Artes Médicas, 2001, 180 p.

FREIRE, P. Cartas à Guiné Bissau. Registro de uma experiência em processo. São Paulo: Paz e Terra, 2014. $272 \mathrm{p}$.

FREITAS, S. N. (2008). Prefácio. In: (Org.). Tendências contemporâneas de inclusáo. Santa Maria: Editora UFSM, 2008, p. 15-18.

GIDDENS, A. As consequências da modernidade. 5. ed. São Paulo: UNESP, 2012. 180 p.

GOFFMAN, E. Estigma. Notas sobre a manipulação da identidade deteriorada. Tradução de Márcia Bandeira de Mello Leite Nunes. 4. ed. Rio de Janeiro: LTC, 2012. 158 p.

HALL, S. A identidade cultural na pós-modernidade. Tradução Humberto Tadeu da Silva e Guacira Lopes Louro. 10. ed. São Paulo: DP\& A, 2005, 102 p.

HARVEY, D.; SOBRAL, A. U. Espaços de esperança. São Paulo: Ediçóes Loyola, 2000. 382 p.

KUHN, T. A estrutura das revoluçóes científicas. 9. ed. São Paulo: Perspectivas, 2006. 220 p. 
LEITE, L. S. (Coord.). Tecnologia educacional. Descubra suas possibilidades em sala de aula. Petrópolis: Vozes, 2003, 119 p.

LOURO, G. L. O corpo educado: pedagogias da sexualidade. 2. ed. Belo Horizonte: Autêntica, 2000. 176 p. MANTOAN, M. T. E. Inclusão escolar: o que é? Por quê? Como fazer?São Paulo: Moderna, 2003. 93 p.

MARCONI, M. de A.; LAKATOS, E. M. Fundamentos de metodológica científica. 6. ed. São Paulo: Atlas. $314 \mathrm{p}$.

MARCUSCHI, L. A.Gêneros textuais: constituição e práticas sociodiscursivas. São Paulo: Cortez, 2010.

MARQUES, C. A.; MARQUES, L. P. A Educação Especial e as mudanças de paradigmas. In: JESUS, D. M.de; BAPTISTA, C. R.; VICTOR, S. L. (Orgs.) Pesquisa e educação especial: mapeando produçôes. Vitória, ES: Edufes, 2006, p. 245-267.

MUNANGA, K. Uma abordagem conceitual das noçôes de raça, racismo, identidade e etnia. In: Seminário Nacional Relaçốes Raciais e Educação, 3º, Rio de Janeiro, 5 nov. 2003. Anais... Rio de Janeiro: PENESB, 2003.

NONATA, A. F. Paradigmas do conhecimento: do moderno ao ecológico. Diálogo Educacional, v. 7, n. 22, p. 259-275, set./dez. 2007.

POPPER, K.Objective knowledge: an evolutionary approach. Oxford: University Press, 1972. 441 p.

ROUSSEAU, J. Discurso sobre a origem e os fundamentos da desigualdade entre os homens. São Paulo: Edipro, 2015. 175 p.

SANCHO, Juana Maria. De tecnologias da informação e comunicação a recursos educativos. In: SANCHO, Juana Maria; HERNÁNDEZ, Fernando. Tecnologias para transformar a educaçáo. Tradução Valério Campos. Porto Alegre: Artmed, 2006, p. 15-42.

SILVA, M. O.E. Da exclusão à inclusão: concepçôes e práticas.Revista Lusófona de Educaçáo, n.13, p. 135-153, 2009. Disponível em: <http://www.scielo.mec.pt/scielo.php?pid=S1645-72502009000100 00100009\&script>. Acesso em: 18 jun., 2017.

VIANNA, C. P.; RIDENTI, S. G. U. Relaçôes de gênero e escola: das diferenças ao preconceito. In: AQUINO, J. G. (coord.). Diferenças e preconceitos na escola: alternativas teóricas e práticas. São Paulo: Summus, 1998, p. $93-106$.

\section{Notas}

${ }^{1}$ Resoluçăo CNE/CEB n. 4, de 13 de julho de 2010.

\section{Correspondência}

Maria Heloisa de Melo Cardoso- Universidade Federal de Sergipe. Av. Marechal Rondon, s / n - Jd. Rosa Elze, São Cristóvão. CEP: 49100-000. Aracaju, Sergipe, Brasil.

E-mail: heloisa.cardoso@ifs.edu.br - veronicamariano@live.com - adelmoliveira@ig.com.br

Correspondências em 16 de novembro de 2017

Final em 20 de março de 2018 